\title{
Microscopy: A tool for quantitative pozzolanic activity in blended cements
}

\author{
C. Costa*, I. Laginha* and P.A. Carvalho**
}

*Área Departamental de Engenharia Civil, Instituto Superior de Engenharia de Lisboa, Rua Concelheiro Emidio Navarro, 1959-007 Lisboa, Portugal.

**ICEMS, Instituto Superior Técnico, Universidade de Lisboa, Av. Rovisco Pais, 1049-001 Lisboa, Portugal

The reuse of waste fluid catalytic cracking (FCC) catalyst, from oil-refinery industry, as a partial substitute of cement is a promising way of reducing the environmental impact of cement production and, therefore, contributes for industrial sustainability. On the other hand partial replacement of cement by oil-cracking catalysts up to $10-15 \%(\mathrm{w} / \mathrm{w})$ results in improved mechanical properties as the waste catalyst tends to react with $\mathrm{Ca}(\mathrm{OH})_{2}$ - liberated upon cement hydration - and forms additional strength-providing reaction products. Nevertheless, the pozzolanic reaction mechanisms between cement and the waste FCC catalyst, which involve Ca migration from the cementitious matrix into the FCC particles is still not well understood $[1,2]$.

In the present study waste FCC catalyst has been incorporated in cement paste mortars with a 15:85 weight ratio. The microstructural evolution of the blended materials has been investigated by X-ray diffraction and scanning electron microscopy coupled with X-ray energy dispersive spectroscopy after curing times of 2, 7 and 28 days. Namely, the evolutions of the catalyst crystal structure and of the calcium content in the dispersed catalyst particles have been evaluated.

The results show that the $\mathrm{Ca} /(\mathrm{Si}, \mathrm{Al})$ ratio in the catalyst particles tends to increase during the cure. However, the inward migration does not occur in a continuous front but rather tends to follow high-diffusivity paths resulting in $\mathrm{Ca}$ depleted rims (Fig. 1). On the other hand the presence of heavy metals resulting from oil-cracking (such as La) remains essentially unaltered after a cure of 28 days. The present study demonstrates that the diffusion of Ca from the surrounding cementitious matrix into the dispersed catalyst particles plays an important role in the pozzolanic activity of the system.

References

1. Costa C. et al., EUROMAT, 6-10 September, Glasgow, UK, 2009.

2. Costa C. et al., Microsc. Microanalys., 18:75-79, 2012.

The authors acknowledge the funding by Fundação para a Ciência e Tecnologia through PTDC/ECM/113115/2009 and PEST-OE/CTM-UI0084/2011 grants. 

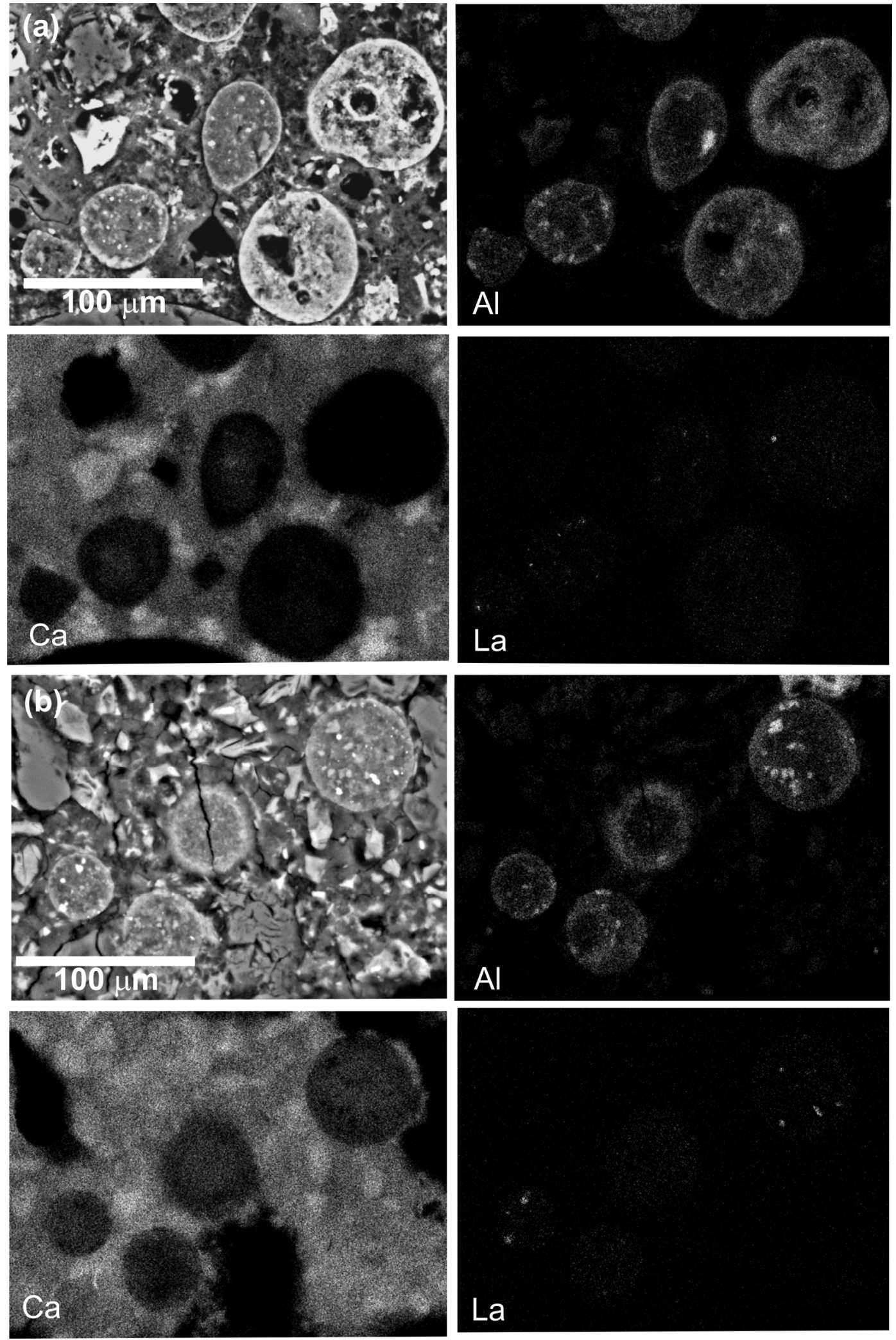

Fig. 1 - BSE-SEM images and corresponding X-ray maps of (a) 7 and (b) 28 days cured mortar with $15 \%$ of waste FCC catalyst incorporation. 